\title{
Current-Injected Load-Modulated Outphasing Amplifier for Extended Power Range Operation
}

\author{
José A. García, Member, IEEE, M. Nieves Ruiz, Ana Cordero and David Vegas
}

\begin{abstract}
In this letter, the power range to be covered with maximized efficiency by a two-way outphasing power amplifier (PA) is significantly extended thanks to a proposed architecture with injection of an external signal. Using a reactively terminated quadrature hybrid coupler (QHC) as non-isolating combiner, the Chireix topology is transformed into a slight variation of the LoadModulated Balanced Amplifier (LMBA) when the auxiliary branch is activated. This combined LM strategy provides a nearly resistive loading of the individual outphasing PAs over a wide power range. An appropriate output network, approximating a class-E/F $/ F_{2}$ operation of the selected GaN HEMT device under such loading condition, leads to remarkable drain efficiency figures at deep output power back-off (OPBO). Values higher than $80 \%$, $70 \%$ and $60 \%$ have been measured at power levels $9.5 \mathrm{~dB}, 13.3 \mathrm{~dB}$ and $15 \mathrm{~dB}$ below its peak $(45.7 \mathrm{dBm})$, respectively. A $5 \mathrm{MHz}$ LTE signal with a peak-to-average power ratio (PAPR) as high as 12.65 $\mathrm{dB}$ has been reproduced with an average efficiency above $62 \%$ and worst case adjacent channel leakage ratio (ACLR) of $-31 \mathrm{dBc}$.
\end{abstract}

Index Terms - Chireix, class-E, LMBA, load modulation, loadpull, outphasing, power amplifier, power efficiency.

\section{INTRODUCTION}

$\mathrm{M}$ ODERN wireless systems continuously advance in the use of spectrum-efficient modulation schemes to accommodate high-data rates within restricted frequency bands. The resulting signals show unprecedented peak-to-average power ratio values, while the linearity requirements are harder to satisfy. Linear amplifiers with high power efficiency at deep OPBO need to be designed, relying on supply modulation and/or load modulation strategies [1]. Given the limitation for implementing wide bandwidth envelope amplifiers with high current and voltage capability, load modulation techniques have been receiving increased attention. Although the simplicity of its input signal splitter has made the Doherty PA a more common choice than others, outphasing and particularly the LMBA architecture are gaining in attractiveness. In the first case, an unbeatable efficiency profile may be obtained when using class-E PAs [2]. In the latter, the desired active LM operation may be guaranteed over a very wide bandwidth [3].

Individually, the above mentioned techniques use to offer a limited efficiency enhancement at back-off levels larger than 8$9 \mathrm{~dB}$, reason why multiway or combined solutions [4], [5] seem

Manuscript received February xx, 2021; revised xxx xx, 2021; accepted xxx xx, 2021. Date of publication xxx xx, 2021; date of current version xxx x, 2021. (Corresponding author: José A. García). This work was supported by the Spanish Ministry of Economy and Competitiveness through the project TEC2017-83343-C4-1-R, co-funded with FEDER. D. Vegas thanks the support provided by the BES-2015-072203 grant. to be unavoidable. Doherty-outphasing LM PAs have been demonstrated [6], [7] for extremely deep OPBO operation, taking advantage of the common use both topologies make of $\lambda / 4$ impedance inverters. In this paper, the principle behind the LMBA is used for extending the power range to be covered with maximized efficiency by a two-way GaN HEMT class-E/ $\mathrm{F}_{2}$ [8] outphasing amplifier, thanks to the non-isolating combining performance offered by a reactively terminated QHC [9], [10] and the injection of an external control signal.

\section{CurRent-Injected LM OUtPhasing ARCHITECTURE}

In Fig. 1a, a simplified diagram of the proposed architecture is presented. Amplifiers 1 and 2 operate as branches of a twoway outphasing topology, playing a sort of carrier PA role. A third amplifying branch is added as auxiliary, control or peaking PA, aimed to extend the power range operation of the outphasing with maximized efficiency. When the auxiliary PA is at its OFF-state, an appropriate length of transmission line transforms its highly reflective output impedance into a reactive termination, $Z_{\text {term }}=-j \cdot X_{\text {term }}=-\mathrm{j} \cdot 50 \Omega$, for the QHC port isolated from the output. As depicted in Fig. $1 \mathrm{~b}$ and Fig. 1c, under such terminating condition and given $I_{\text {aux }}=0$, the QHC performs as a Chireix combiner [10]. Varying the outphasing angle, $\Delta \theta$, the input impedance values at $\mathrm{RF}_{\text {in } 1}$ and $\mathrm{RF}_{\text {in } 2}$ describe horizontally oriented trajectories, centered along the resistive axis. The compensating reactances, $-j \cdot X_{\text {comp }}$ and $j \cdot X_{\text {comp }}$, play their typical role, reducing the imaginary part of the input impedance and adjusting the compensating angles, $\Delta \theta_{c}$, for which a pure resistance may be synthesized. A moderate-range outphasing operation was set in Fig. 1c using $X_{\text {comp }}=200 \Omega$.

The control current, $I_{a u x}$, injection is recommended when the outphasing topology is operating at the high power or low resistive loading $\Delta \theta_{H P_{c}}$ value (see Fig. 1c). The outphasing angle needs to be slightly readjusted with the input power to the auxiliary PA or the $I_{a u x}$ value, in order the mutual LM trajectories of the outphasing PAs stay coincident. The desired orientation along the resistive axis may be guaranteed with a fixed phase value for $I_{a u x}$ [3]. As it may be appreciated from Fig. $1 \mathrm{c}$, the combined trajectories for the phase-coded (PhC-) and current-injected (CI-) LM modes show much smaller reactive components if compared to those due to a wide-range Chireix.

Jose A. García, M. Nieves Ruiz, Ana Cordero and David Vegas are with the Department of Communications Engineering, University of Cantabria (UC), 39005 Santander, Spain. (e-mail: joseangel.garcia@unican.es).

Color versions of one or more of the figures in this letter are available online at http://ieeexplore.ieee.org.

Digital Object Identifier XXXXXXXXXXXXXX 


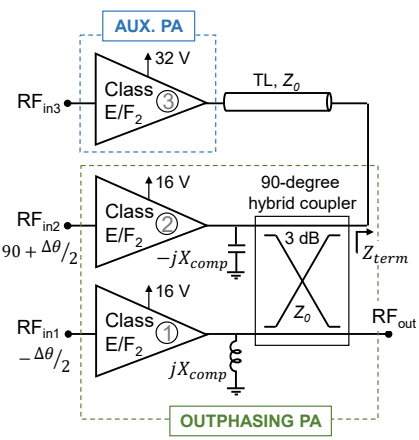

(a)

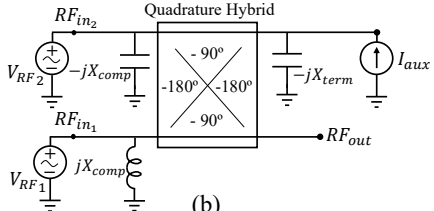

(b)

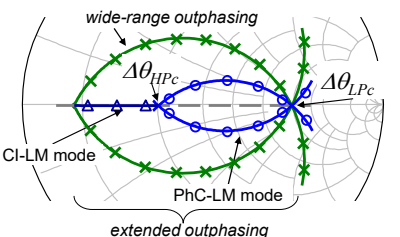

(c)
Fig. 1. (a) Diagram representation of the proposed architecture, (b) simplified schematic for the QHC-based combiner operation, and (c) comparison of LM trajectories for $\mathrm{PA}_{1}$ and $\mathrm{PA}_{2}$ due to a combined or extended outphasing $(\mathrm{PhC}$ $\mathrm{LM}+\mathrm{CI}-\mathrm{LM}$ modes) versus a conventional wide-range outphasing operation.

\section{Class-E/F 2 POWER AMPlifier TOPOLOGY}

\section{A. Device selection and biasing conditions}

The $700 \mathrm{MHz}$-band design of the involved PAs is based on the CGH35030F packaged GaN HEMT from WolfSpeed. The drain DC voltage values for the outphasing and control PAs ( $V_{D S O}=16 \mathrm{~V}$ and $V_{D S C}=32 \mathrm{~V}$, respectively) were selected to allow an appropriate dimensioning of the required injection current, while also avoiding the peak in the drain-to-source voltage waveforms to reach breakdown. The gate DC voltage for the PAs integrating the outphasing topology $\left(V_{G S O}=-3.4 \mathrm{~V}\right)$ was initially adjusted just below the value for which some increase in the output conductance could be appreciated. In Fig. $2 \mathrm{a}$, the evolution of the $\mathrm{S}_{22}$ parameter with frequency for the device biased at $V_{G S O}=-3.4 \mathrm{~V}$ and $V_{D S O}=16 \mathrm{~V}$ is represented. A marker provides the value at the second harmonic, $1.4 \mathrm{GHz}$. The control PA gate biasing voltage was set to a lower value $\left(V_{G S C}=-6 \mathrm{~V}\right)$, as typical in amplifiers with a peaking function.

\section{B. Drain terminating network}

The load-insensitive class-E/ $\mathrm{F}_{2}$ topology in Fig. $2 \mathrm{~b}$ [11], was selected both for the carrier and peaking PAs. Although the auxiliary amplifier is not aimed to work under varying load condition, the minimization of conduction losses [8] may have a positive impact on the overall efficiency performance.

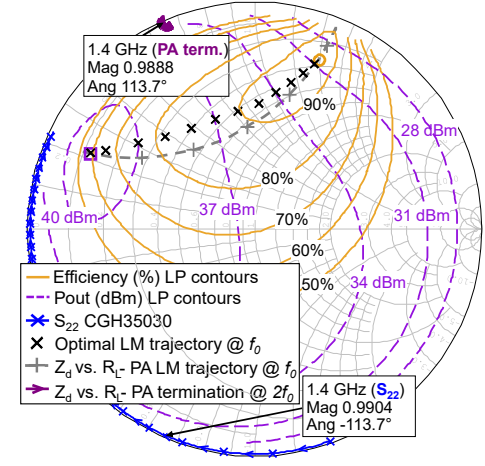

(a)

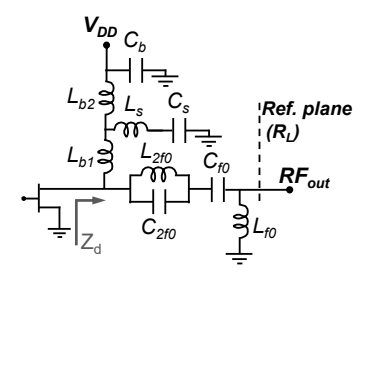

(b)
Fig. 2. (a) Simulated LP contours at $V_{G S O}=-3.4 \mathrm{~V}$ and $V_{D S O}=16 \mathrm{~V}$ with the synthesized LM trajectory at $700 \mathrm{MHz}$ and the $1.4 \mathrm{GHz}$ termination. The optimal LM path at the fundamental frequency and the $\mathrm{S}_{22}$ parameter of the CGH35030F GaN HEMT have been also added. (b) Schematic of the output network for approximating a class-E/ $\mathrm{F}_{2}$ load-insensitive operation.
With the $L_{2 f 0} C_{2 f o}$ and $L_{s} C_{s}$ circuits tuned at $1.4 \mathrm{GHz}, L_{b 1}$ is responsible for providing the termination required for resonating $C_{\text {out }}$ at $2 \cdot f_{0}\left(1 \angle 113.7^{\circ}\right) . L_{b 2}$ was adjusted in order to force the drain biasing network to act as a RF choke at 700 MHz. $C_{f o}$ and $L_{f 0}$ are in charge of synthesizing a LM trajectory at the fundamental close to the optimum (the one composed by the impedance points providing maximum efficiency at each output power level). This trajectory and the $2 \cdot f_{0}$ termination were added to Fig. 2a, together with the load-pull (LP) contours.

\section{EXTENDED ClASS-E/F $\mathrm{F}_{2}$ OUTPHASING OPERATION}

The evolution of the load impedance at the fundamental, as seen from the drain terminals of the devices in the outphasing branches $\left(\mathrm{PA}_{1}\right.$ and $\left.\mathrm{PA}_{2}\right)$, have been included in Fig. 3a over the corresponding LP contours. The extended outphasing technique, combining a moderate-range phase-coded with a current-injected LM mode, is here compared to an equivalent wide-range outphasing scheme operating up to $10 \mathrm{~dB}$ below the peak power value. In Fig. 3b, the evolution of the outphasing angle and the normalized injected current as a function of output power are presented for each case. As it may be appreciated from Fig. 3a, the combined or extended operation leads to LM trajectories closer to the optimum, reason why an improved efficiency profile could be expected. Attending to the advantages of the mixed-mode approach [6] for reproducing the lowest part of a high PAPR signal envelope, the linear operation of the PAs integrating the outphasing topology in Fig. 1a has been also included in Fig. 3. The LM trajectories when the outphasing angle is kept equal to $\triangle \theta_{H P c}$, while increasing the injected current, have been finally added in order to visualize the benefits obtained when readjusting this angle with $I_{a u x}$, as proposed in this work.

In Fig. 4, the resulting efficiency versus output power, $P_{\text {out }}$, profiles are presented for each of the cases. The power provided by the injection source has been included in the calculations. The losses in the class-E/ $\mathrm{F}_{2}$ topology selected for $\mathrm{PA}_{1}$ and $\mathrm{PA}_{2}$ impose a limit to the maximum efficiency to be obtained from their outphasing operation. The proposed extended or combined technique (PhC-LM + CI-LM modes) leads to an improved performance at deep OPBO, as a consequence of a LM operation of $\mathrm{PA}_{1}$ and $\mathrm{PA}_{2}$ closer to the optimum as well as of the entire recovery of the injected power at the output port [3], [9]. The power losses in the control amplifier, $\mathrm{PA}_{3}$, would impact the CI-LM mode profile at intermediate $P_{\text {out }}$ values.

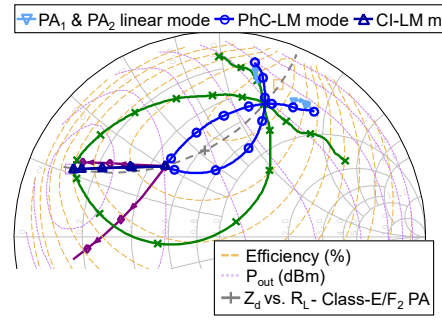

(a)

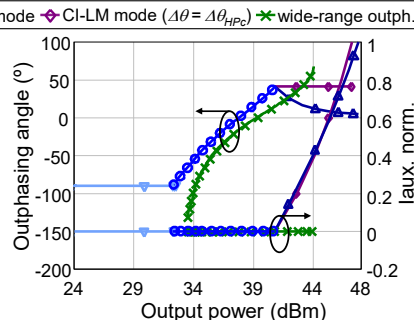

(b)
Fig. 3. (a) LM trajectories for different operation modes over the output power and efficiency contours. (b) Outphasing angle and $I_{a u x}$ variation, normalized to its maximum 1.6 A value, with output power for each case. 


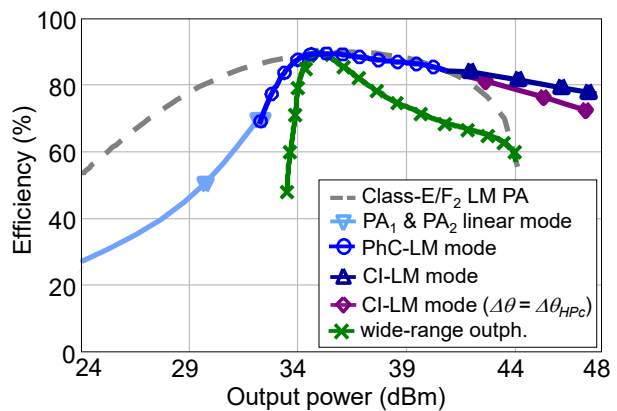

Fig. 4. Efficiency versus output power profiles for different operation modes as obtained from simulations.

\section{IMPLEMENTATION AND CHARACTERIZATION RESULTS}

In Fig. 5a and Fig. 5b, the schematic and a photograph of the implemented architecture are shown. The 11304-3S QHC from Anaren Inc. was selected. The compensating susceptances were incorporated into the output networks of $\mathrm{PA}_{1}$ and $\mathrm{PA}_{2}$ (left side). High-Q air-core coils from Coilcraft and multilayer ceramic capacitors from ATC were employed. The control amplifier (right side) is connected to the QHC through a $50 \Omega$ transmission line. A set of SMA transitions allowed fitting the required electrical length, but it could be substituted by a lumped-element equivalent in an integrated version.

\section{A. CW characterization}

The implemented three-way architecture was measured following the mixed-mode outphasing (linear + PhC-LM) and peaking (CI-LM) operating modes. The results appear in Fig. 6.

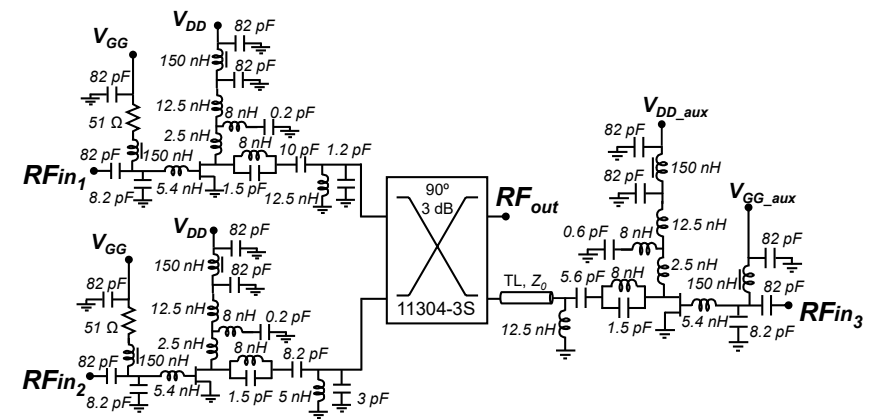

(a)

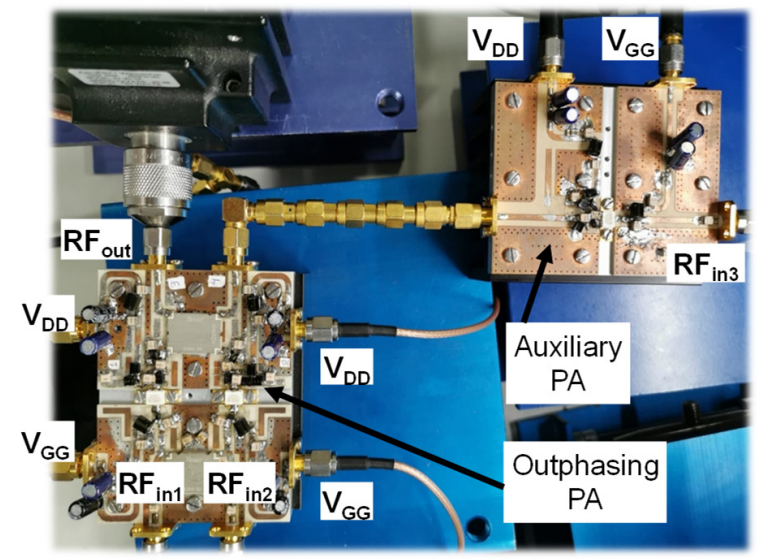

(b)

Fig. 5. Implemented outphasing architecture: (a) schematic and (b) photograph.

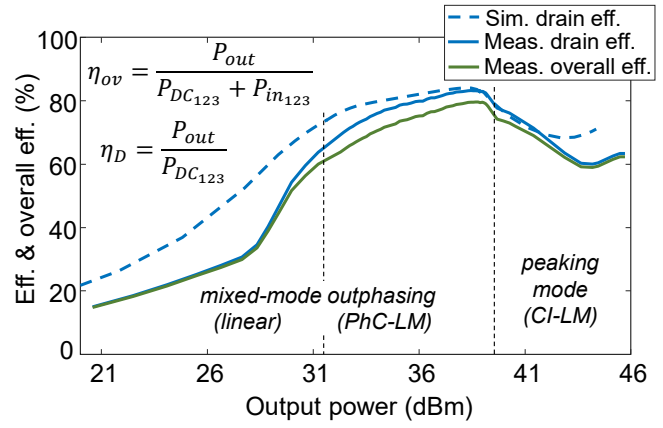

Fig. 6. Simulated (--) and measured (-) drain efficiency, $\eta_{D}$, versus output power profiles for the complete architecture. The measured overall efficiency, $\eta_{o v}$, which includes the carrier and peaking input RF power, has been added.

In outphasing mode, an output power of $38.9 \mathrm{dBm}$ may be achieved with overall and drain efficiency values of $79.4 \%$ and $82.9 \%$, respectively. It may be increased up to $45.7 \mathrm{dBm}$ (a 6.8 $\mathrm{dB}$ extension) thanks to the CI-LM or peaking mode, with a worst case drain efficiency of $60 \%$. Although the measured profile shows differences with respect to the simulation, remarkable figures above $80 \%, 70 \%$ and $60 \%$ were obtained at OPBO values of $9.5 \mathrm{~dB}, 13.3 \mathrm{~dB}$ and $15 \mathrm{~dB}$, respectively.

\section{B. Dynamic characterization}

The hardware was tested using a $5 \mathrm{MHz}$ LTE signal with a highly demanding $12.65 \mathrm{~dB}$ PAPR. An average efficiency of $62 \%$ and an ACLR better than $-31 \mathrm{dBc}$ were measured, without applying any dedicated digital predistortion (DPD). A customized composite memory polynomial behavioral model [12] can be considered in order to satisfy the in-band and outof-band linearity requirements. Attending to the narrowband nature of the class-E/ $\mathrm{F}_{2}$ topology selected for validation, the performance is expected to degrade for signals with a bandwidth wider than $20 \mathrm{MHz}$. Table I compares the results to those from representative state-of-the-art GaN HEMT multiway LM PAs. Incorporating reported variations in outphasing [13] and LMBA [14], the proposed three-way architecture could be made to operate from a single RF input.

TABLE I
COMPARISON WITH GAN STATE-OF-THE ART MULTI-WAY LOAD-MODULATEd PAS

\begin{tabular}{|c|c|c|c|c|c|c|c|c|}
\hline Ref. & Circuit type & $\begin{array}{c}f_{0} \\
(G H z)\end{array}$ & $\begin{array}{l}\eta_{\text {peak }} \\
(\%)\end{array}$ & 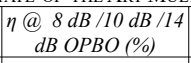 & $\begin{array}{c}P_{\text {out } \max } \\
(\mathrm{W})\end{array}$ & $\begin{array}{c}\text { Signal/PAPR } \\
(d B)\end{array}$ & $\begin{array}{l}\eta_{\text {avg }} \\
(\%)\end{array}$ & $\begin{array}{l}\text { ACLR } \\
(\mathrm{dBc})\end{array}$ \\
\hline [7] & $\begin{array}{c}\text { Doherty- } \\
\text { Outphasing }\end{array}$ & 0.58 & 77.7 & $76.5^{*} / 74 / 64.5^{*}$ & 131.8 & $\begin{array}{c}\text { LTE } 10 \mathrm{MHz} / \\
11.9 \\
\end{array}$ & 66.6 & $-50.3^{\dagger}$ \\
\hline $\begin{array}{l}\text { This } \\
\text { work }\end{array}$ & & & 83.2 & $82.75 / 79.3 / 65.21$ & 37.4 & $\begin{array}{c}\text { LTE } 5 \text { MHz / } \\
12.65 \\
\end{array}$ & 62 & -31 \\
\hline [15] & $\begin{array}{r}\text { PD-D } \\
\text { LM }\end{array}$ & 0.7 & 82 & $58^{*} / 64 / 45^{*}$ & 15.8 & $\begin{array}{c}\text { LTE } 10 \mathrm{MHz} / \\
9.5\end{array}$ & 62 & -24 \\
\hline [16] & $\begin{array}{r}\text { PD-Do } \\
\text { LMI } \\
\end{array}$ & $1.5-2.7$ & 72 & $\begin{array}{l}59^{*} / 58 / 34^{*} \\
\text { (@1.7 GHz) }\end{array}$ & 19.9 & $\begin{array}{c}\text { LTE } 10 \mathrm{MHz} / \\
9.5 \\
\end{array}$ & 58 & -25.8 \\
\hline [6] & & 2.14 & 66 & $60^{*} / 56^{*} / 38.5^{*}$ & 112 & - & - & - \\
\hline [4] & $\begin{array}{l}\text { Four-Stage } \\
\text { Doherty }\end{array}$ & 2.14 & 77 & N.R. & 100 & $\begin{array}{l}\text { WCDMA } 3.84 \\
\mathrm{MHz} / 6.5\end{array}$ & 61 & -31 \\
\hline
\end{tabular}

\section{CONCLUSION}

An architecture with injection of an external signal has been proposed for extending the power range to be covered with maximized efficiency by a two-way outphasing PA. Implemented at UHF-band, based on a load insensitive $\mathrm{GaN}$ HEMT class-E $/ \mathrm{F}_{2}$ topology, efficiency figures higher than $80 \%$, $70 \%$ and $60 \%$ have been measured at power levels $9.5 \mathrm{~dB}, 13.3$ $\mathrm{dB}$ and $15 \mathrm{~dB}$ below its peak $(45.7 \mathrm{dBm})$. 


\section{REFERENCES}

[1] F. H. Raab et al., "Power amplifiers and transmitters for RF and microwave," IEEE Trans. Microwave Theory Tech., vol. 50, no. 3, pp. 814-826, Mar 2002.

[2] R. Beltran, F. H. Raab and A. Velazquez, "HF outphasing transmitter using class-E power amplifiers," IEEE MTT-S Int. Microw. Symp. Dig., Boston, MA, USA, June 2009, pp. 757-760.

[3] R. Quaglia and S. Cripps, "A load modulated balanced amplifier for telecom applications," IEEE Trans. Microwave Theory Tech., vol. 66, no. 3, pp. 1328-1338, March 2018.

[4] A. Grebennikov, "A high-efficiency $100-\mathrm{W}$ four-stage Doherty GaN HEMT power amplifier module for WCDMA systems," IEEE MTT-S Int. Microw. Symp. Dig., Baltimore, MD, USA, June 2011, pp. 1-4.

[5] T. Cappello, T. W. Barton, C. Florian, M. Litchfield and Z. Popovic, "Multilevel supply-modulated Chireix outphasing with continuous input modulation," IEEE Trans. Microwave Theory Tech., vol. 65, no. 12, pp. 5231-5243, Dec. 2017.

[6] A. R. Qureshi, M. Acar, J. Qureshi, R. Wesson and L. C. N. de Vreede, "A $112 \mathrm{~W}$ GaN dual input Doherty-outphasing power amplifier," IEEE MTT-S Int. Microw. Symp. Dig., San Francisco, CA, USA, June 2016, pp. 1-4.

[7] A. Yamaoka, T. M. Hone and K. Yamaguchi, "70 \% Efficient Dual-Input Doherty-Outphasing Power Amplifier for Large PAPR Signals," IEEE MTT-S Int. Microw. Symp. Dig., Boston, MA, USA, June 2019, pp. 556559.

[8] S. D. Kee, I. Aoki, A. Hajimiri and D. Rutledge, "The class-E/F family of ZVS switching amplifiers," IEEE Trans. Microwave Theory Tech., vol. 51, no. 6, pp. 1677-1690, June 2003.
[9] D. J. Collins, R. Quaglia, J. R. Powell and S. C. Cripps, "The orthogonal LMBA: a novel RFPA architecture with broadband reconfigurability," IEEE Microw. Wireless Comp. Lett., vol. 30, no. 9, pp. 888-891, Sept. 2020.

[10] A. Cordero, M. Nieves Ruiz, D. Vegas and J. A. García, "Outphasing class- $\mathrm{E} / \mathrm{F}_{2}$ power amplifier using a quadrature hybrid as non-isolating combiner," presented at IEEE Topical Conference on RF/Microwave Power Amplifiers for Radio and Wireless Applications, Virtual Conference, 2021

[11] D. Vegas, J. Perez-Cisneros, M. N. Ruiz and J. A. García, "UHF class $\mathrm{E} / \mathrm{F}_{2}$ outphasing transmitter for $12 \mathrm{~dB}$ PAPR signals," IEEE MTT-S Int. Microw. Symp. Dig., Boston, MA, USA, 2019, pp. 71-74.

[12] P. L. Gilabert, et al., "Design and digital predistortion linearization of a wideband outphasing amplifier supporting $200 \mathrm{MHz}$ bandwidth," IEEE Topical Conference on RF/Microwave Power Amplifiers for Radio and Wireless Applications, San Antonio, TX, USA, 2020, pp. 46-49.

[13] T. W. Barton and D. J. Perreault, "Theory and implementation of RFinput outphasing power amplification," IEEE Trans. Microwave Theory Tech., vol. 63, no. 12, pp. 4273-4283, Dec. 2015.

[14] P. H. Pednekar, E. Berry and T. W. Barton, "RF-input load modulated balanced amplifier with octave bandwidth," IEEE Trans. Microwave Theory Tech., vol. 65, no. 12, pp. 5181-5191, Dec. 2017.

[15] Y. Cao and K. Chen, "Dual-octave-bandwidth RF-input pseudo-Doherty load modulated balanced amplifier with $\geq 10$-dB power back-off range," IEEE MTT-S Int. Microw. Symp. Dig., Los Angeles, CA, USA, 2020, pp. 703-706.

[16] Y. Cao and K. Chen, "Pseudo-Doherty load-modulated balanced amplifier with wide bandwidth and extended power back-off range," IEEE Tran. Microwave Theory Tech., vol. 68, no. 7, pp. 3172-3183, July 2020. 